\title{
TÍTULO DE ESPECIALISTA EM CIRURGIA DO APARELHO DIGESTIVO
}

\section{Certification in Surgery of the Alimentary Tract}

\author{
Henrique Walter PINOTTI*
}

ABCDDV/644

Pinotti HW. Título de especialista em cirurgia do aparelho digestivo. ABCD Arq Bras Cir Dig 2009;22(2):71

Depois da Segunda Guerra Mundial, “1939-1945”, surgiu grande progresso em diferentes áreas da atividade humana. A indústria aperfeiçoou seus métodos de produção centrados principalmente na qualidade. Na área da medicina, sobretudo da cirurgia, emergiram inúmeras inovações respeitando o princípio na prática de operações com aprimoramento técnico com a atenção voltada para a qualidade.

Entende-se de boa qualidade a intervenção praticada com esmero, sequência, compreendendo os seus fundamentos como acesso, dissecção, ressecção e reconstituição, obedecendo aos princípios do bom acabamento, estético e limpo, sem contaminações obedecendo aos princípios da fisiopatologia e funções das estruturas trabalhadas. Em casos de intervenções em neoplasias, deve respeitar as bases da ressecção com margens de segurança, e da remoção dos territórios linfonodais afetados.

O pensamento cirúrgico refletiu e concluiu que a qualidade dependia da especialização e padronização. A especialização na área da medicina e na cirurgia foi uma necessidade para melhorar o conhecimento do campo de atividade. A padronização do ato cirúrgico foi decisão fundamental para melhorar a qualidade das intervenções cirúrgicas.

No Brasil, no Hospital das Clínicas da Universidade de São Paulo, a partir de 1952, o Professor Alípio Correa Netto, estabeleceu a instalação de "grupos" que eram constituídos por cirurgiões dedicados a setores da cirurgia com o objetivo de conhecerem melhor os meios diagnósticos das afecções e a prática de operações padronizadas, isto é, operações sistematizadas de modo racional e repetitíveis.

Esses grupos de especialistas adquiriram consistente experiência, e acumulando casuísticas cirúrgicas, trouxeram contribuição científica para as propostas da realização criteriosa de procedimentos técnicos e estímulos para as inovações. Tornaram o ato cirúrgico assimilável pelos residentes facilitando a sua prática com competência. Os

\section{* Fundador do Colégio Brasileiro de Cirurgia Digestiva -} CBCD

Endereço para correspondência: Henrique Walter Pinotti, e-mail: cbed@cbed.org.br grupos especializados difundiram seus conhecimentos em publicações de revistas e livros, e apresentações em congressos que vieram fortalecer o conceito da especialização.

Com a instituição da reforma universitária, em 1969 e criação do sistema departamental, os grupos especializados passaram a constituir as disciplinas e o conjunto das disciplinas afins passou a formar os departamentos.

A instalação da disciplina de Cirurgia do Aparelho Digestivo foi excelente oportunidade para a criação da residência especializada em Cirurgia do Aparelho Digestivo, em 1981. Em 1986, fundamos o Colégio Brasileiro de Cirurgia Digestiva pioneiro nas Américas e dos raros no mundo.

Posteriormente, a intensa procura por cirurgiões interessados e o resultado social do seu trabalho profissional levaram o Conselho Federal de Medicina a reconhecer a especialidade de Cirurgia do Aparelho Digestivo em 1994.

A consolidação da especialidade em Cirurgia do Aparelho Digestivo estimulou o interesse de inúmeros cirurgiões e foi fonte de atrativos para que instituições universitárias e hospitalares isoladas criassem cursos de residência em Cirurgia do Aparelho Digestivo, envolvendo hoje no Brasil, 29 programas em pleno andamento.

O Colégio Brasileiro de Cirurgia Digestiva, atento à necessidade de obrigar profissionais a praticar intervenções cirúrgicas com competência, visando às finalidades sociais, procurou, imediatamente, certificá-los.

Certificar significa reconhecer a sua qualificação profissional e aptidão para diagnóstico e tratamento de pacientes com afecções do aparelho digestivo, até as de maior complexidade.

A realização de provas escrita, prática e análise de curriculum vitae constitui a base da rigorosa avaliação dos candidatos por comissões constituídas por especialistas experientes.

No período de 1991 a 2007, apresentaram-se 1960 candidatos com índice de aprovação de $65 \%$ ou 1269 aprovados.

A intenção do Colégio Brasileiro de Cirurgia Digestiva é que seus membros exerçam a especialidade, com todo rigor ético e técnico, atualizando seus conhecimentos de modo continuado, para beneficiar seus pacientes, promovendo o prestígio da especialidade e do Colégio Brasileiro de Cirurgia Digestiva.

\footnotetext{
Fonte de financiamento: não ha Conflito de interesse: não há Recebido para publicação: 19/01/2009 Aceito para publicação: 16/03/2009
} 